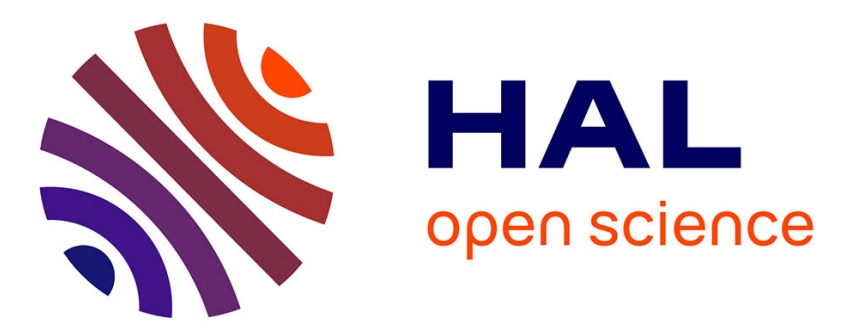

\title{
Investigating Seismic Behavior of Reinforced Concrete Columns with SFRP Using Finite Element Method
}

\author{
Jalil Khani, Mohsen Bozorg, Seyed Mehdi Zahrai
}

\section{To cite this version:}

Jalil Khani, Mohsen Bozorg, Seyed Mehdi Zahrai. Investigating Seismic Behavior of Reinforced Concrete Columns with SFRP Using Finite Element Method. American Journal of Engineering and Applied Sciences, 2018, 10.3844/ofsp.12023 . hal-01822336

\section{HAL Id: hal-01822336 \\ https://hal.science/hal-01822336}

Submitted on 25 Jun 2018

HAL is a multi-disciplinary open access archive for the deposit and dissemination of scientific research documents, whether they are published or not. The documents may come from teaching and research institutions in France or abroad, or from public or private research centers.
L'archive ouverte pluridisciplinaire HAL, est destinée au dépôt et à la diffusion de documents scientifiques de niveau recherche, publiés ou non, émanant des établissements d'enseignement et de recherche français ou étrangers, des laboratoires publics ou privés. 


\title{
Investigating Seismic Behavior of Reinforced Concrete Columns with SFRP Using Finite Element Method
}

\author{
${ }^{1}$ Jalil Khani, ${ }^{2}$ Mohsen Bozorg and ${ }^{3}$ Seyed Mehdi Zahrai \\ ${ }^{1}$ Islamic Azad University, Takestan, Iran \\ ${ }^{2}$ Imam Khomeini International University, Qazvin, Iran \\ ${ }^{3}$ School of Civil Engineering, The University of Tehran, Tehran, Iran
}

\author{
Article history \\ Received: 24-04-2018 \\ Revised: 24-05-2018 \\ Accepted: 31-05-2018 \\ Corresponding Author: \\ Seyed Mehdi Zahrai, \\ School of Civil Engineering, \\ The University of Tehran, \\ Tehran, IranEmail: \\ mzahrai@ut.ac.ir
}

\begin{abstract}
Currently, various methods have been used for repairing and retrofitting reinforced concrete columns including Steel Fiber Reinforced Polymer (SFRP) jackets in order to improve load bearing capacity. However, the enclosure mechanism is less known by consideration of the effects of slender columns which needs much more studies. Avoiding the buckling of a slender Reinforced Concrete (RC) column against the compressive axial force using SFRP is the main aim of this research. One of the parametrical studies in this paper is the influence of the number of layers that is investigated by Finite Element Method (FEM). Accordingly, in this paper, several RC columns are modeled under the Manjil earthquake record and the force-displacement curves of each model are numerically calculated. The columns are divided into three groups: the first group is non-SFRP and the subsequent groups are reinforced by one and two layers of SFRP. At first, three-dimensional models of the columns were prepared by ABAQUS finite element software and then by applying axial load and seismic forces, the parametric effect on behavior of the columns has been investigated. The results show that the retrofitting of the column with SFRP increases the flexural and stiffness, which plays a significant role in reducing the buckling of the $\mathrm{RC}$ columns.
\end{abstract}

Keywords: Steel Fiber Reinforced Polymer (SFRP), Reinforced Concrete Column, Seismic Loading, ABAQUS

\section{Introduction}

Because of the earthquake effects during two recent decades, retrofitting and repairing $\mathrm{RC}$ structures has become the most common method for strengthening of structure in which the most typical material has been FRP (Toutanji et al., 2010). In this case, using SFRP was one of the most useful ways to increase capacity of structure. Țaranu et al. (2011) conducted some experiments on RC structures using Carbon Fiber Reinforced Polymer (CFRP) and found that using FRP materials can specifically improve the behavior of RC columns and ductility of RC elements. Nashley et al. (2008) used pre-stressed FRP to improve the seismic behavior of concrete elements. The results of this study showed that using FRP prevents the shear failure and improves the load bearing capacity of RC columns. Soleimani and Roudsari (2015; Roudsari et al., 2018) numerically studied the behavior of RC beams under extreme loading condition. They used ABAQUS software in order to find out the effect of FRP sheets and bars on the strength and ductility of the RC beams. Their loading condition was as impact loading in different height and velocity and their results showed that using FRP bars had better performance than FRP sheets. Moreover, Fallahi et al. (2018) validated their results regarding RC frame with masonry infill wall using different geometry of retrofitting of CFRP sheet. Their results indicated that diagonal retrofitting had much better performance for increasing strength and energy absorption. In other cases, Herwig and Motavalli (2012) studied on square columns retrofitted by GFRP layers. Or even Abdelrahman and El-Hacha (2012) conducted experiments on large size RC columns retrofitted using CFRP and SFRP. Pan et al. (2007) carried out experimental investigation on slender RC column 
retrofitted by FRP sheets. Although there are a few studies about different kinds of reinforced concrete elements, there is no attractive solution for improving the behavior of reinforced concrete structures. On the other hand, studies are mostly experimental and numerical studies by finite element method are required to predict the behavior of these criteria which can decrease the cost in terms of time and experimental expenses. Also, by considering the importance of the structural performance at the time of the earthquake, the necessity of this study becomes more vital to predict the seismic behavior of RC columns.

\section{Modeling}

In order to simulate the experimental results with FEM models, Ţaranu et al. (2011) studied using ABAQUS Software to perform the simulations by finite element method. In their modeling, a solid ThreeDimensional Eight-Node Element (C3D8R) for concrete element, a truss one-dimensional element for the reinforcement elements and a four-node shell element for membrane (S4R) were modeled. Geometrical features of experimental work are shown in Fig. 1. In Fig. 2 the details of modeling are shown. It should be noted that, validating of models were compared in two ways with the results of the model: 1. Non-reinforced column mode; 2. Column reinforced with layers.

Moreover, in order to define the concrete behavior, the concrete damage plasticity model is used. In fact, the parametrical study of this model has been done by Roudsari et al. (2018) which has been exploited using different parameters regarding compressive and tensile behavior of concrete and its damages. They used MATLAB toolbox to validate their result by numerical models.
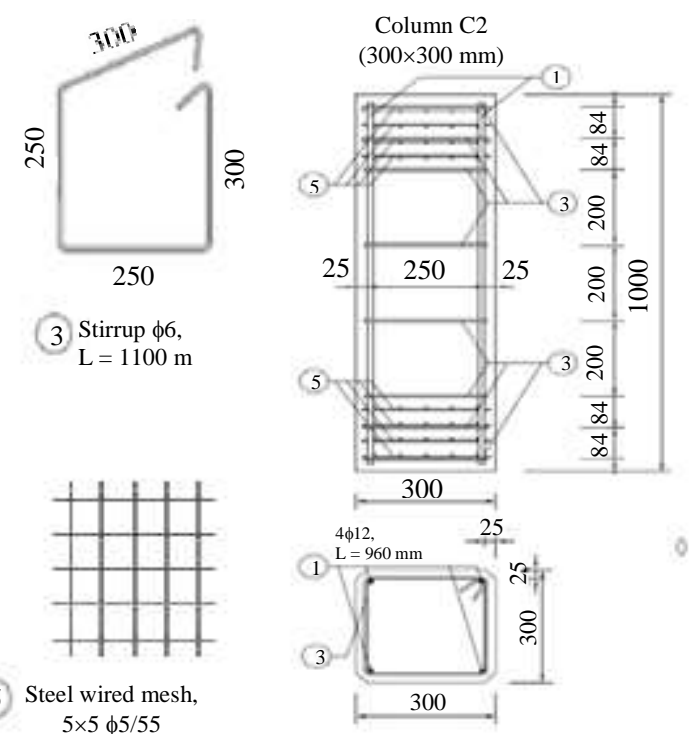

Fig. 1: Details of the experimental work (Ţaranu et al., 2011)

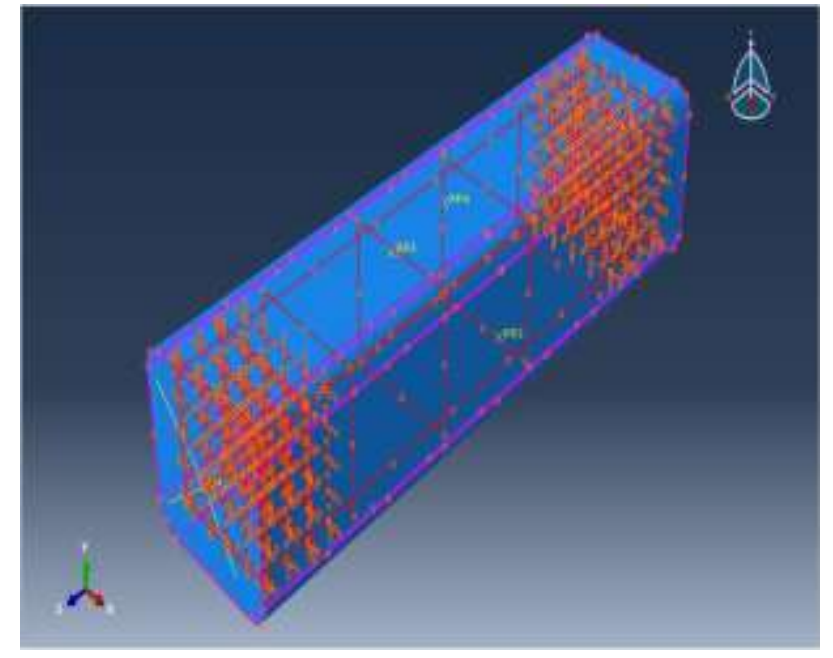

Fig. 2: Details of the test column

Moreover, they followed another investigation to use these parameters in ABAQUS software to analyze the effects of arbon Fiber Reinforced Polymer (CFRP) and Garbon Fiber Reinforced Polymer (GFRP) sheets on large size RC columns. Their results indicated that using CFRP has better performance in strength and ductility.

\section{Results and Discussion}

In Figs. 3, 4 \& 5 the stress contour of S22, S33 and S11 of column without retrofitting are shown in $\mathrm{x}$ and $\mathrm{z}$ axis, respectively. In Figs. 6 and 7 the perpendicular plane with one layer column is shown, but unlike the column without retrofitting, in retrofitted column most areas are under compression. In Fig. 8, the contour of the S33 stress is shown for the longitudinal axis of the column, which like the column without retrofitting, this column is compressed on one side of the stress column and on the other side, it has pure tensile stress.

In Fig. 9, the curve of numerical results is shown which carried out two kind of displacements including transvers and axial direction for tensile and compression sides.

The results are shown by blue and red line which were related to column without retrofitting and column retrofitted with one layer, respectivvely. As it is clear the numerical and experimental results are compared well. In the term of transvers displacement graph, the maximum load for experimental sample C2-1 tension is about $2260 \mathrm{kN}$ compared with $2245 \mathrm{kN}$ for numerical results. Also, in the longitudinal displacement graph and in the tension part, the maximum load for C2-1 sample for numerical and experimental results are $2247 \mathrm{kN}$ and $2504 \mathrm{kN}$, respectively. 


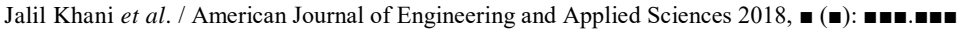
DOI: 10.3844/ajeassp.2018.men.mm

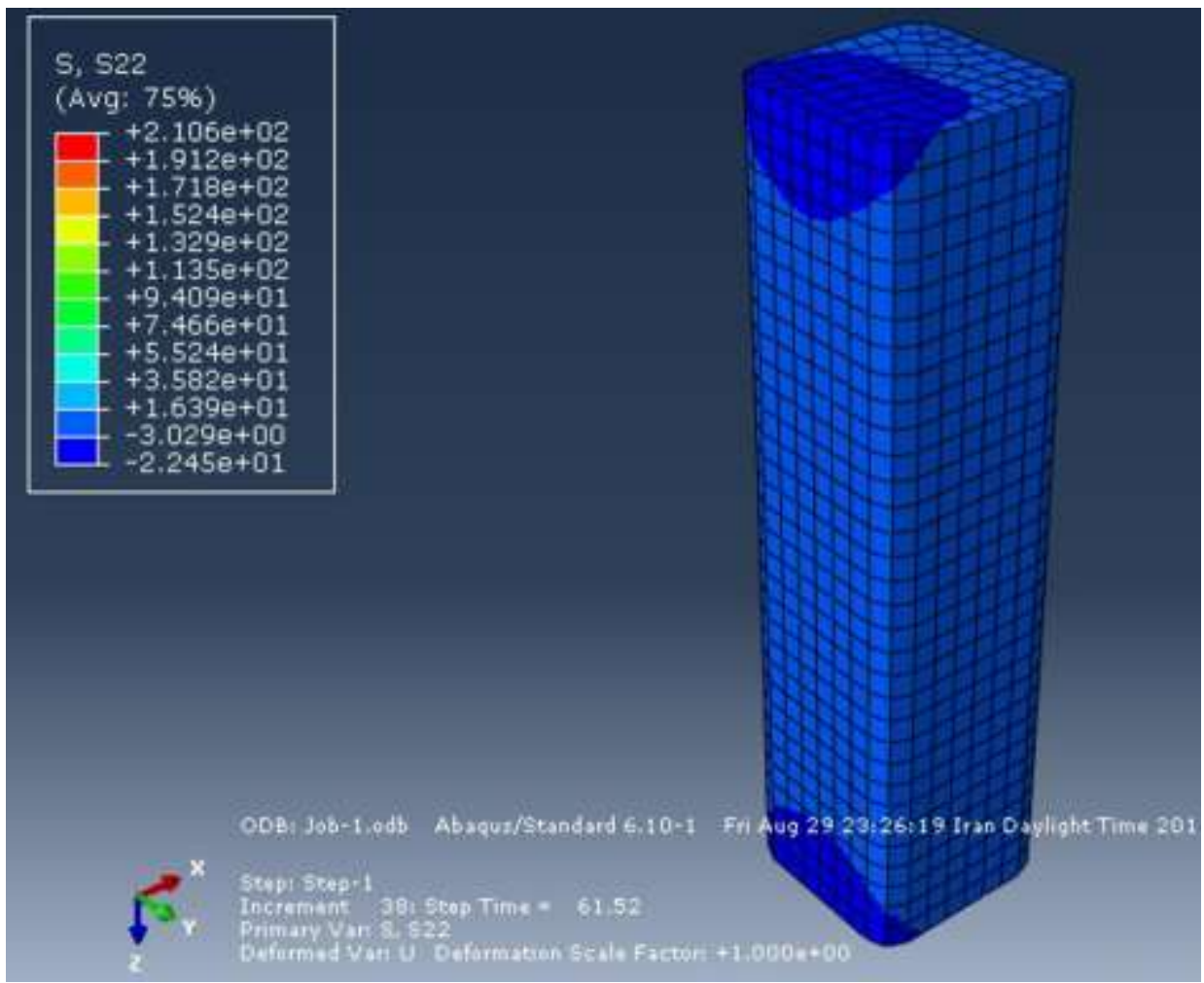

Fig. 3: Vertical tension in y direction- column without layer

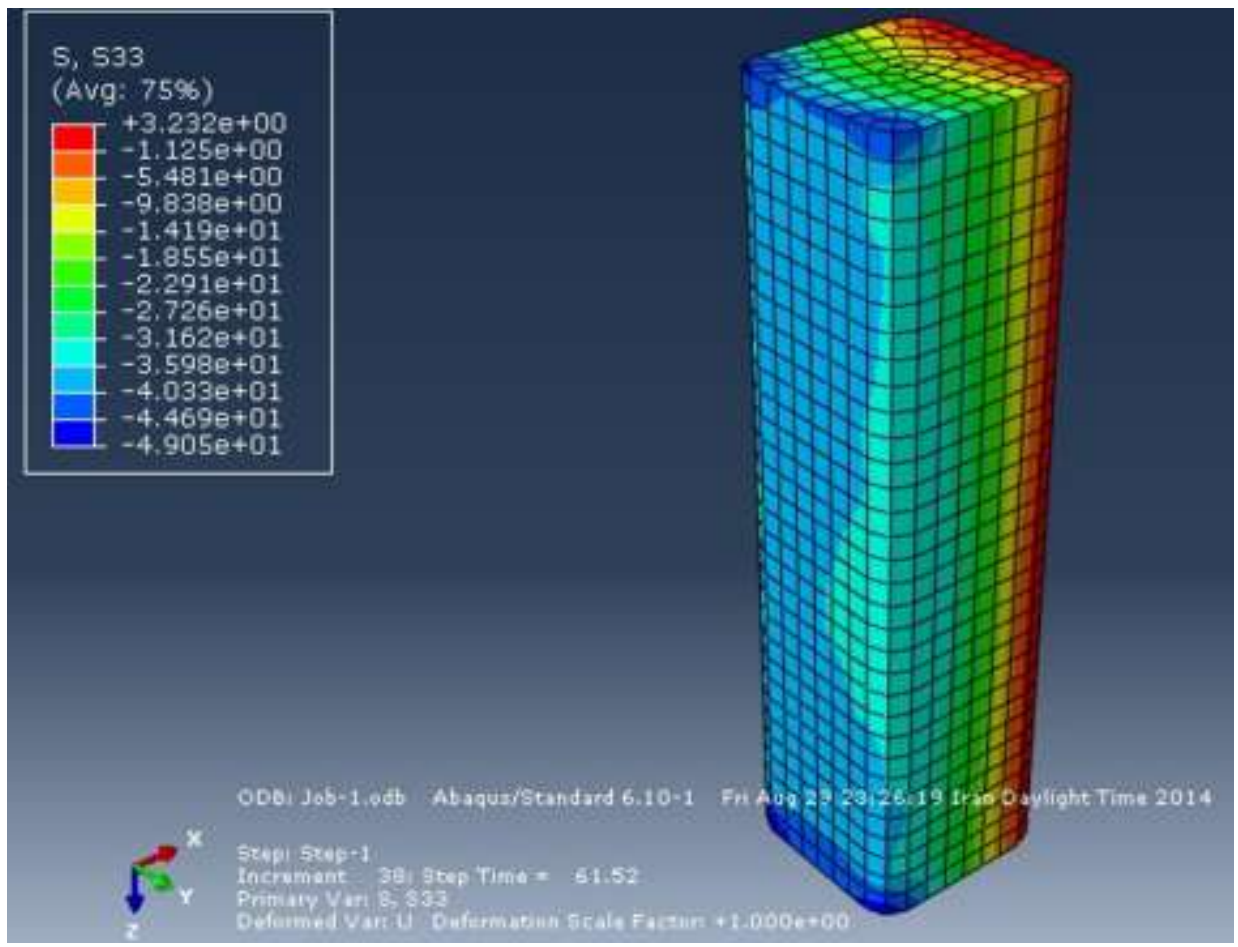

Fig. 4: Vertical tension in z direction- column without layer 


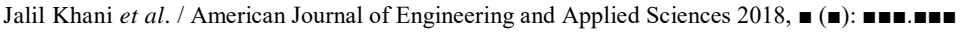
DOI: 10.3844/ajeassp.2018.man.men

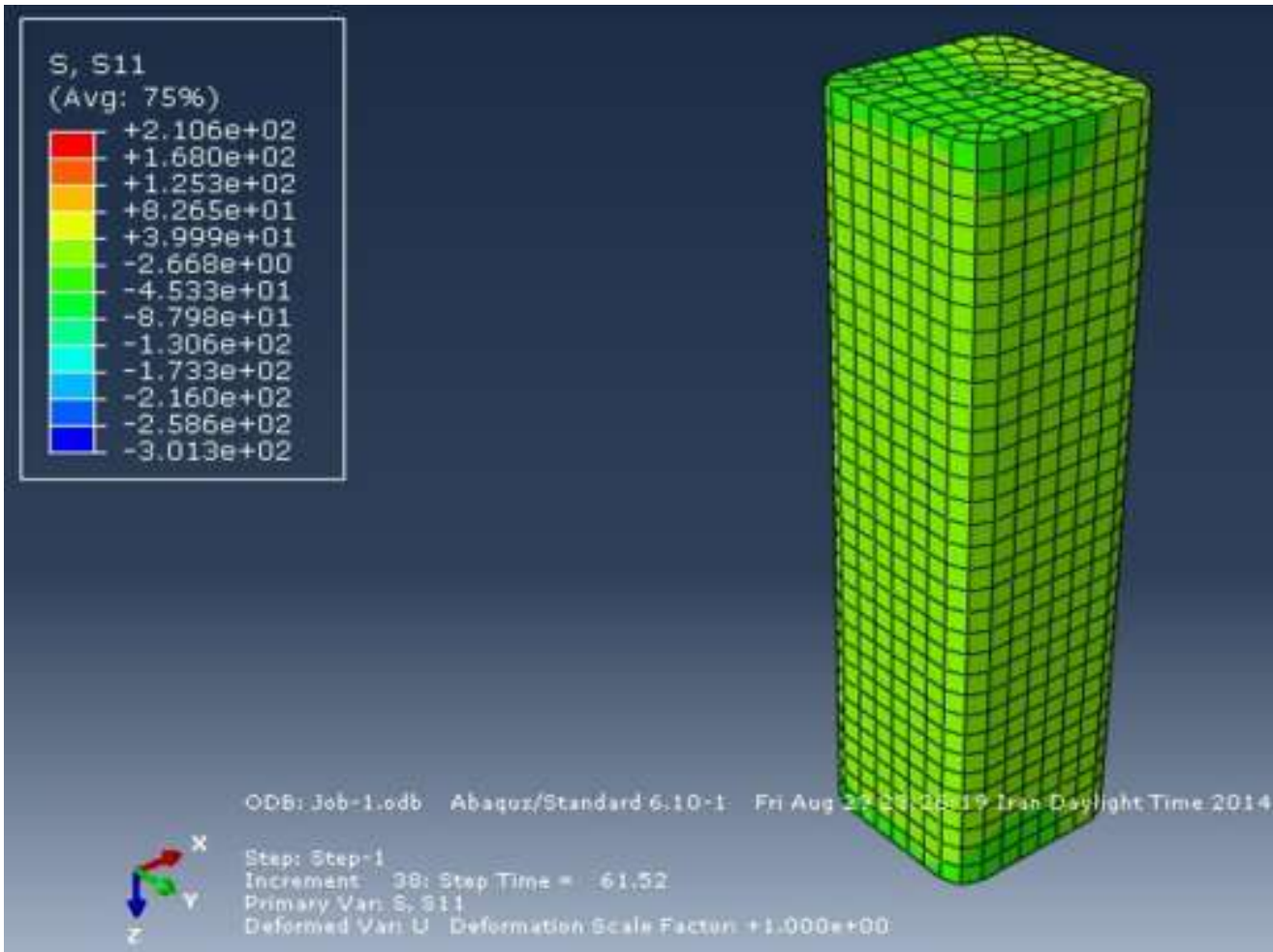

Fig. 5: Vertical tension in the $\mathrm{x}$ direction - column without layer

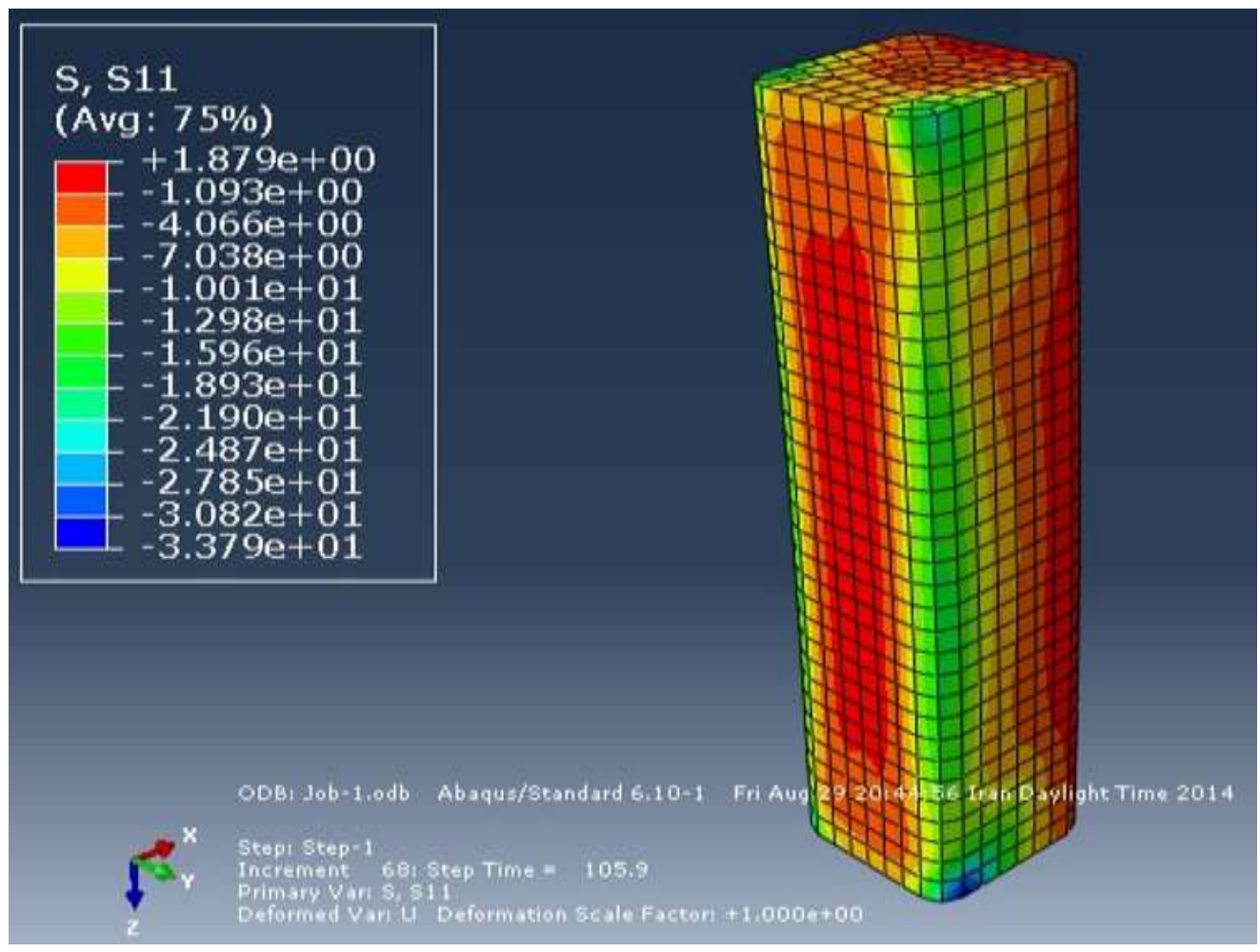

Fig. 6: Vertical tension in $\mathrm{x}$ direction- column reinforced with a layer 


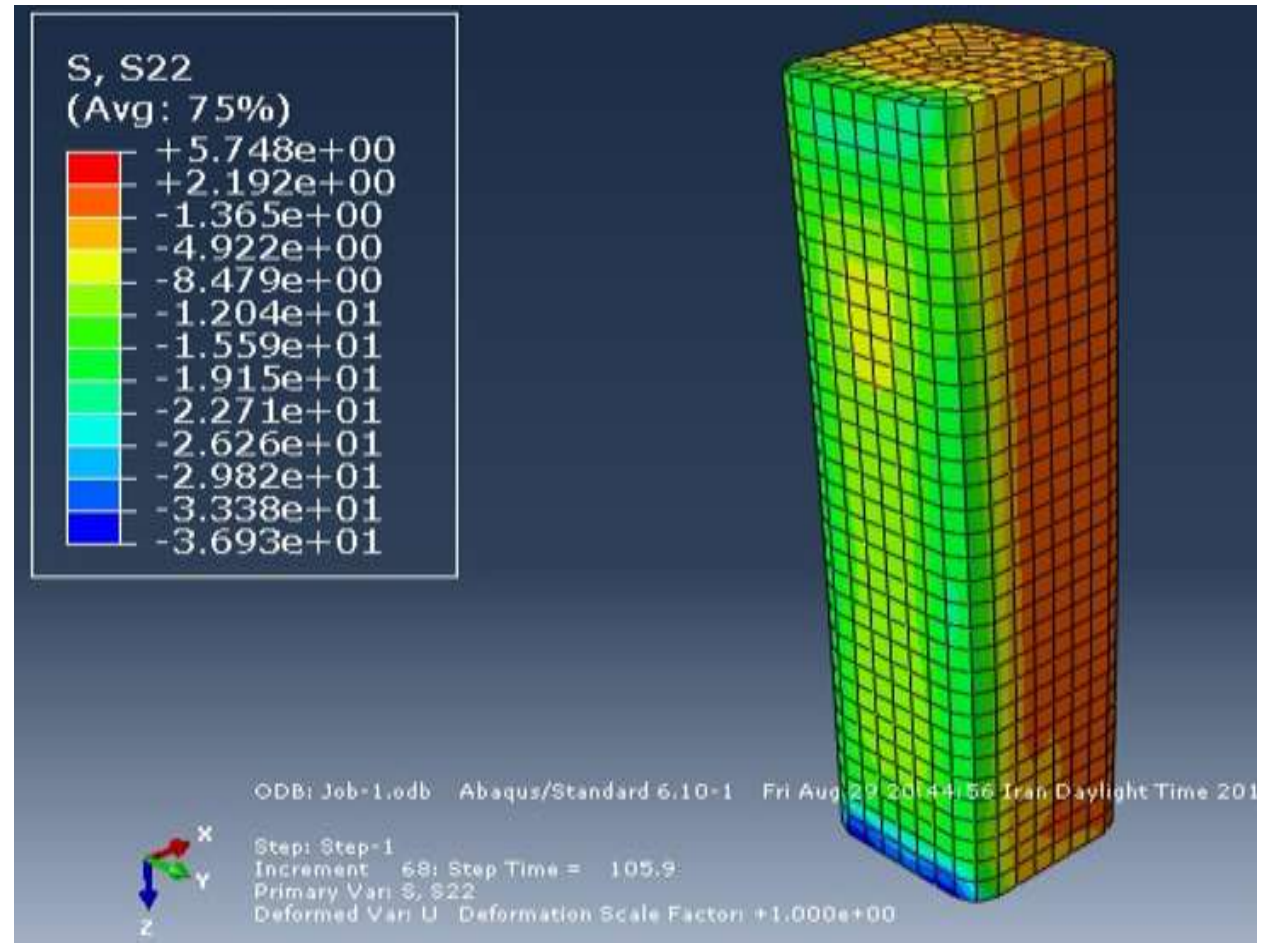

Fig. 7: Vertical tension in the y direction - column reinforced with a layer

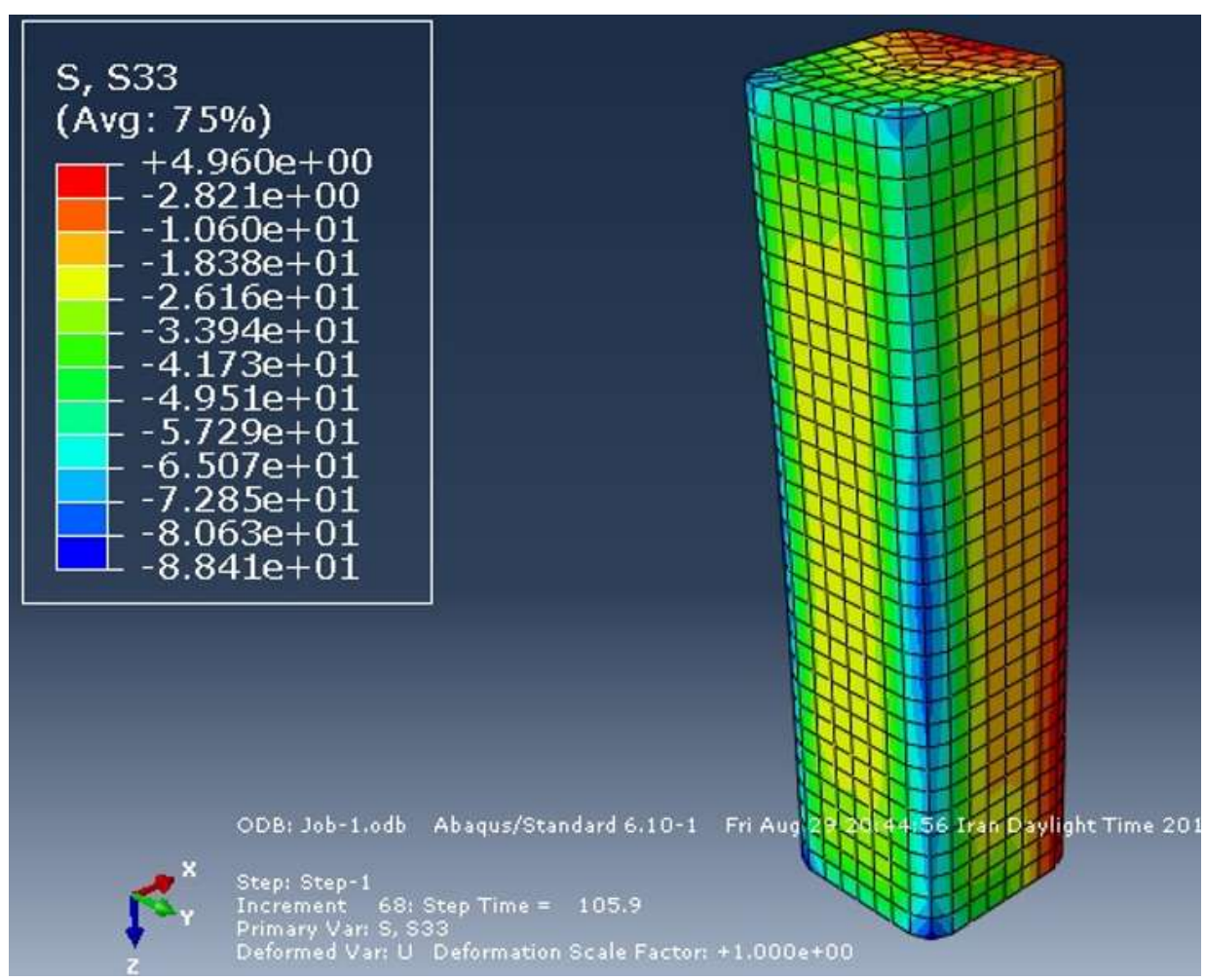

Fig. 8: Vertical tension in z direction - column reinforced with one layer 


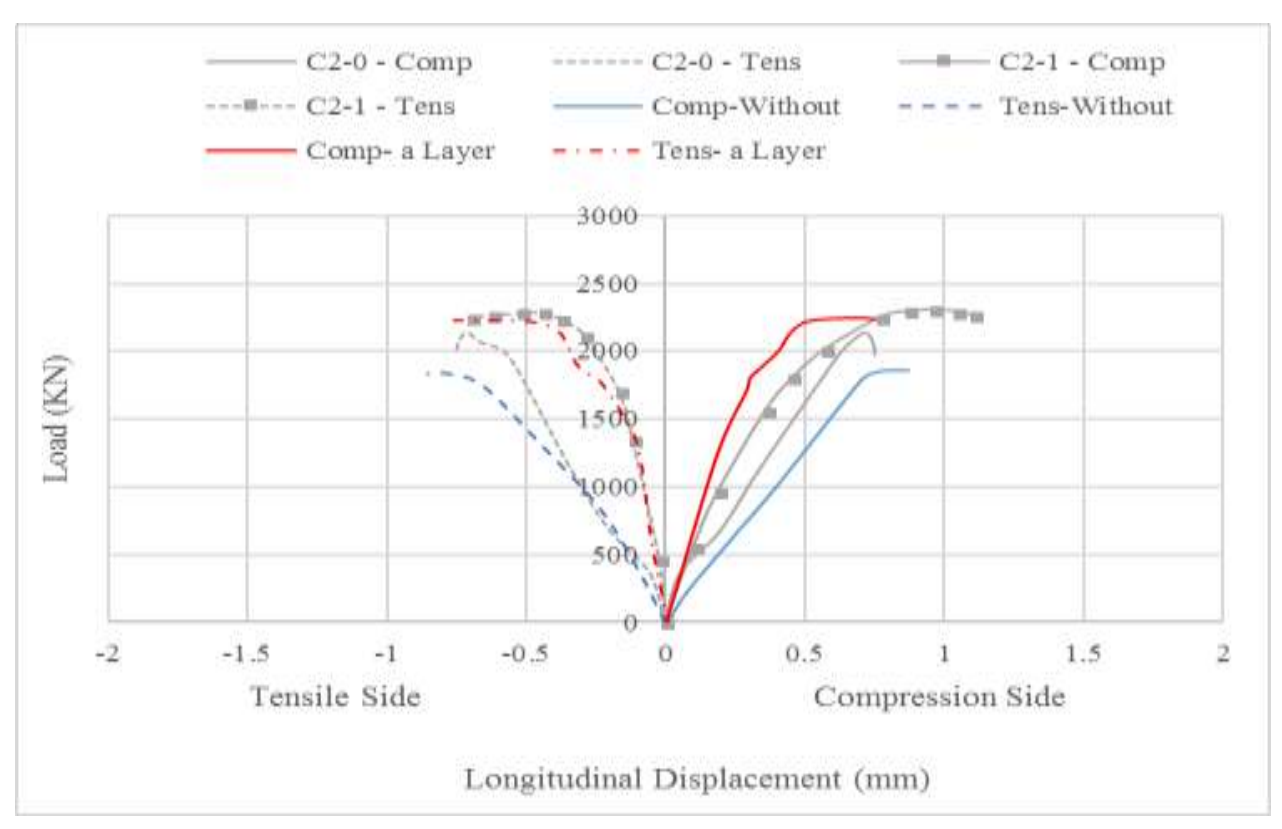

Fig. 9: Comparison of numerical results curves with experimental results

\section{Parametrical Study of Slender Columns}

This part is about seismic behavior of (RC) reinforced concrete columns using finite element software and then, studying the reinforcement of slender columns using one and two layers of SFRP under seismic loads including combining lateral seismic and axial load. Time-history analysis of the of the column has been performed under horizontal and vertical seismic loading conditions. The Dynamic Explicit analysis has been used for all models, using time-acceleration amplitude from the Manjil earthquake record, that recorded in Abhar with PGA=13.00g. The horizontal and vertical acceleration of this earthquake is shown in Fig. 10. A $90 \mathrm{kN}$ load is considered to be the equivalent of mass at the place where the dynamic force is applied. Also, the other end is fixed means, $\mathrm{U} 1=\mathrm{U} 2=\mathrm{U} 3=\mathrm{UR} 1=\mathrm{UR} 2=\mathrm{UR} 3=0$. Due to geometric symmetry and loading, the half column is modeled (Pan et al., 2007).

The result of time-history analysis is shown in Fig. 11 for columns without retrofitting and with one and two layers of SFRP. Also, the diagram is shown in Figs.12 and 13 , for $\mathrm{y}$ and $\mathrm{z}$ directions, respectively.

Fig. 11 shows that column displacement response depends on the number of layers. In fact, the displacement

increases, when less layers are used. So, confinement of the column with SFPR layers can have extreme effect on decreasing the failures which caused by dynamic buckling columns.
Fig. 12 declares that increasing the number of layer caused reduction in vertical displacement for horizontal load on Y axis. So, SFRP layer can be effective to avoid of torsion buckling. In fact, the displacement decreases on $\mathrm{Y}$ axis (retrofitted by one layer) about $40.5 \%$ and with two layers is about $55.5 \%$ compared with column without retrofitting. In the Fig. 13, the results of analysis in $\mathrm{Z}$ direction are shown which indicate that the effect of one layer is $23.3 \%$ and with two layers is $47.7 \%$ more in comparison with column without retrofitting.

Hysteresis curve of load-displacement for column under horizontal and vertical loading is shown on Fig. 14. The results show that increasing the number of layers decreases ductility. In addition, increasing the number of layers caused reduction risk of buckling of columns and related failure.

As it is clear in Fig. 15, in the $\mathrm{z}$ direction also increasing number of layers reduces the maximum displacement. So, using SFRP layers can decrease ductility that caused the columns remain in inelastic range. 


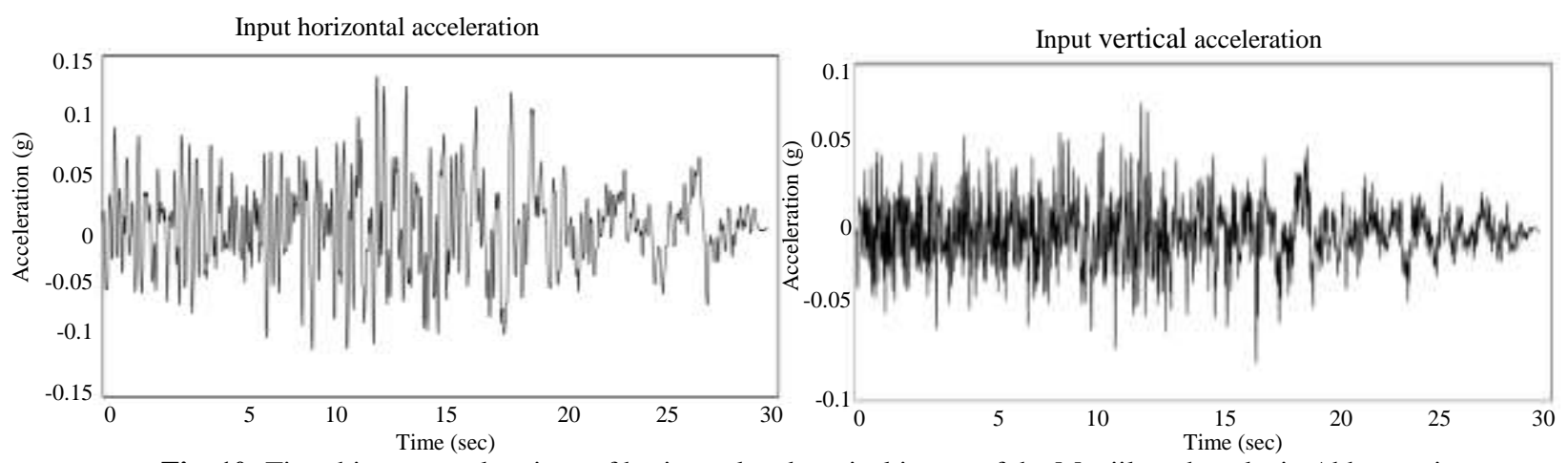

Fig. 10: Time-history accelerations of horizontal and vertical inputs of the Manjil earthquake in Abhar station

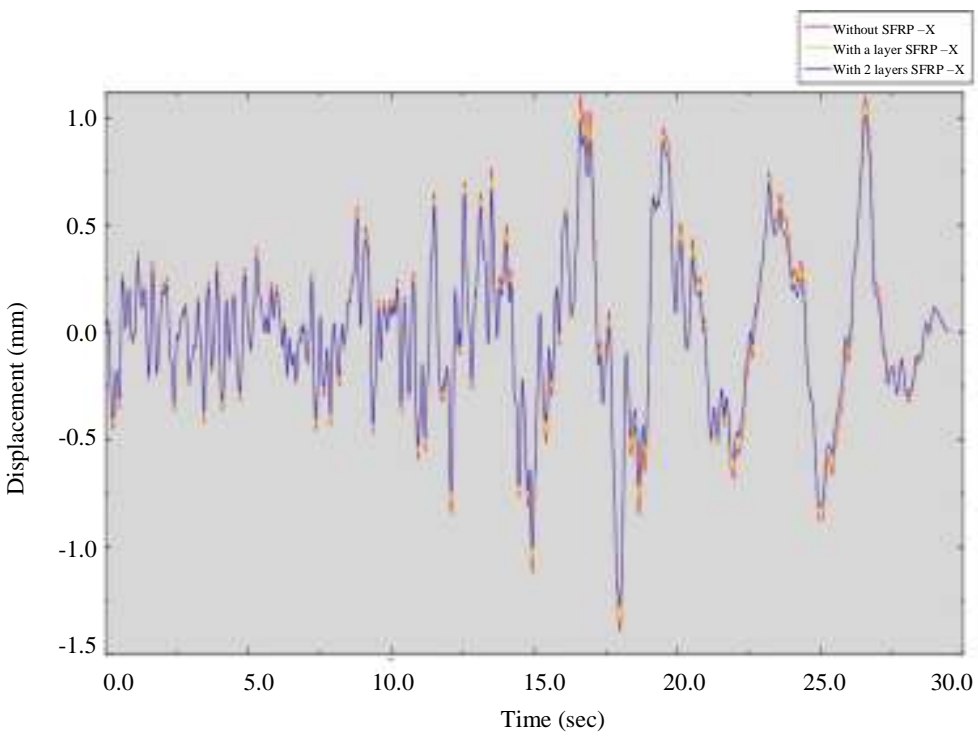

Fig. 11: The time-history diagram in $x$ direction

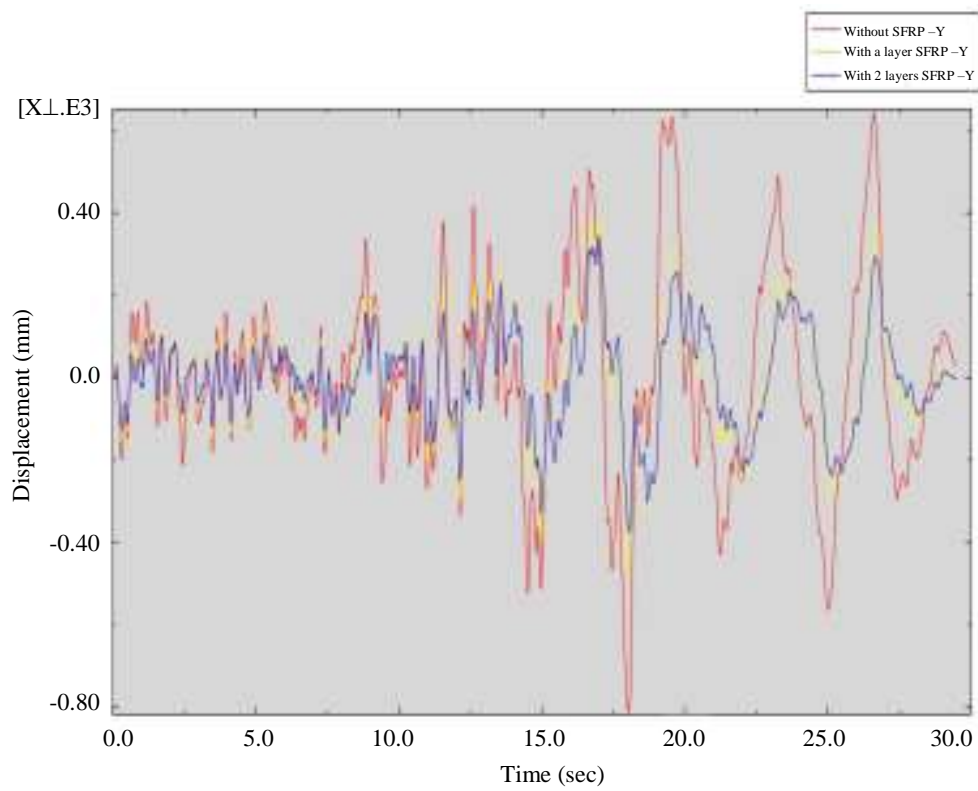

Fig. 12: The time-history diagram in y direction 


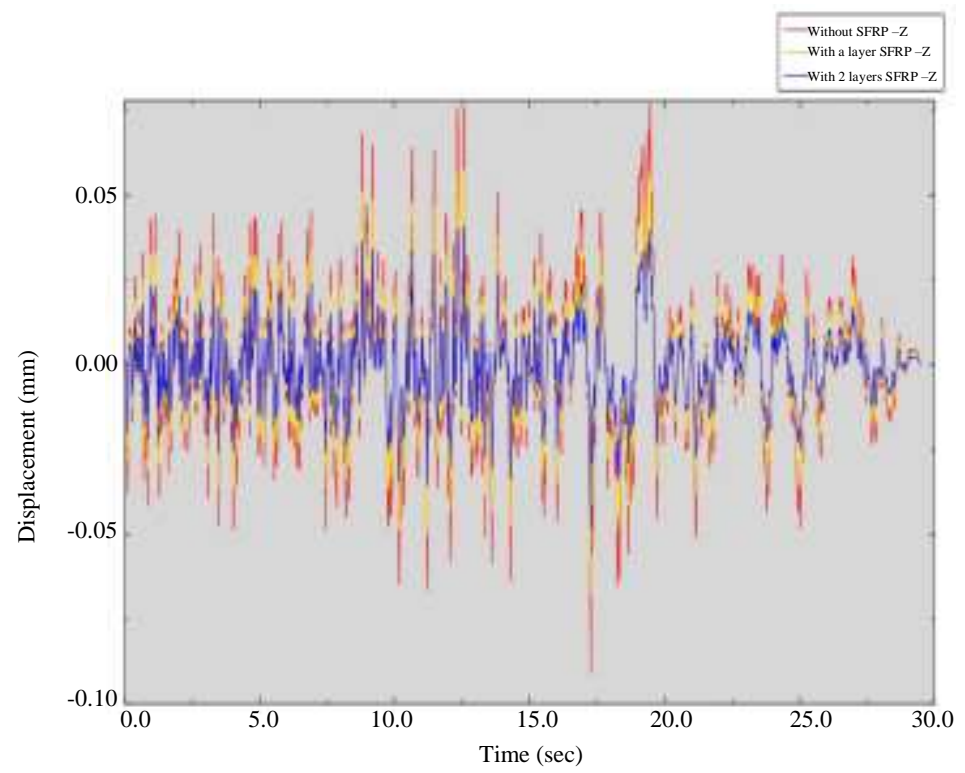

Fig. 13: The time-history diagram in $\mathrm{z}$ direction

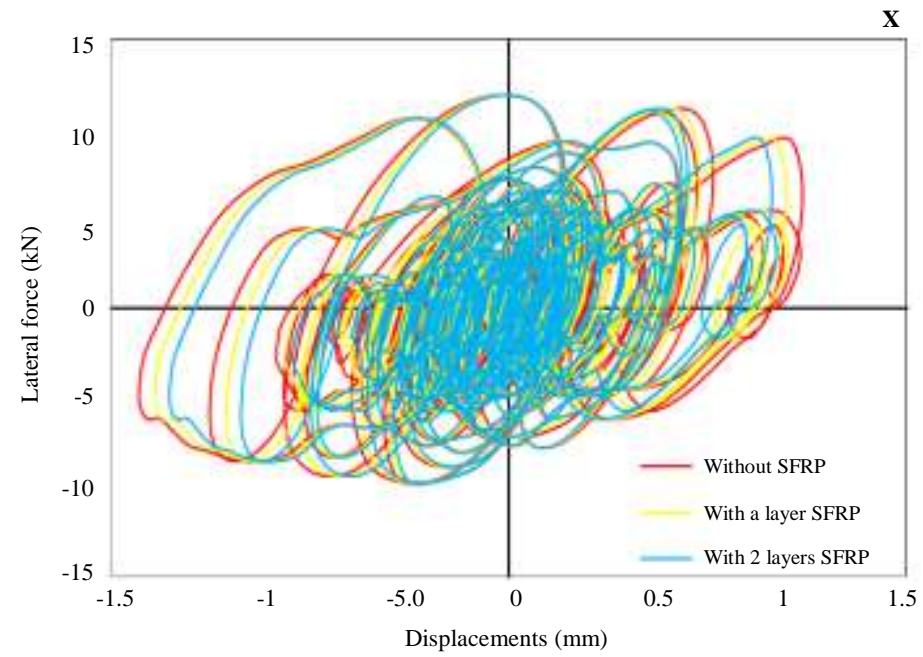

Fig. 14: Hysteresis curves in $x$ axis under horizontal and vertical seismic loads

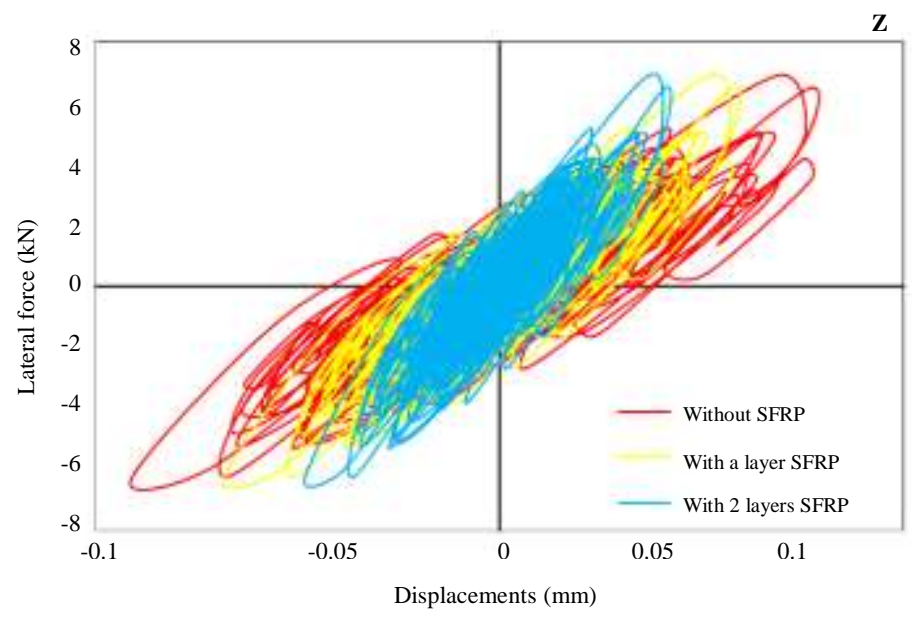

Fig. 15: Hysteresis curves in $\mathrm{z}$ axis 


\section{Conclusion}

In this research, RC columns were retrofitted using one and two SFRP layers. The results are as follow:

- Numerical results have shown that increasing SFRP layers reduced displacement.

- Increasing the number of layers can increase the strength and decrease the ductility.

- Using SFRP can prevent failure under both axial and lateral loads.

- $\quad$ SFRP layers can be useful to prevent the buckling of slender RC columns.

\section{Acknowledgments}

The Authors would like to thank the Islamic Azad university of Takestan, Iran for supporting this research.

\section{Authors' Contributions}

Jalil Khani and Mohsen Bozorg: Performed modeling with ABAQUS software and data analysis. Also, participated in writing the manuscript.

Seyed Mehdi Zahrai: Provided the research topic and guided the research development, experimental verification and data analysis. Also, participated in writing and editing the manuscript.

\section{Ethics}

This article is an original research paper. There are no ethical issues that may arise after the publication of this manuscript.

\section{References}

Abdelrahman, K. and R. El-Hacha, 2012. Behavior of large-scale concrete columns wrapped with CFRP and SFRP sheets. J. Compos. Constr., 16: 430-439.

Fallahi, M., M. Haghighfar, R. Madandoust and S.S. Roudsari, 2018. Modeling of reinforced concrete frames with infill walls under cyclic loading strengthening with CFRP. Submitted J. Eng. Applied Sci. DOI: 10.3844/ajeassp.2018
Herwig, A. and M. Motavalli, 2012. Axial behavior of square reinforced concrete columns strengthened with lightweight concrete elements and unbonded GFRP wrapping. J. Compos. Constr., 16: 747-752.

Nasrollahzadeh Nesheli, K. and K. Meguro, 2006. Seismic retrofitting of earthquake-damaged concrete column by lateralpre-tension of FRP Belts. Proceedings of the 8th U.S. National Conference on Earthquake Engineering, April 18-22, San Francisco, California, USA, Paper No. 841.

Pan, J.L., T. Xu and Z.J. Hu, 2007. Experimental investigation of load carrying capacity of the slender reinforced concrete columns wrapped with FRP. Construction Building Materials, 21: 1991-1996.

Roudsari, S.S., S.A. Hamoush, S.M. Soleimani and R. Madandoust, 2018. Evaluation of large-size reinforced concrete columns strengthened for axial load using fiber reinforced polymers. Construction Building Materials.

Roudsari, S.S., S.A. Hamoush, S.M. Soleimani, T.A. Lebdeh and M. Haghighfar, 2018. Analytical study of reinforced concrete beams strengthened by FRP bars subjected to impact loading condition. A. J. Eng. Applied Sci. DOI: 10.3844/ajeassp.2018

Soleimani, M. and S.S. Roudsari, 2015. Analytical study of reinforced concrete beams tested under impact loading. Proceedings of the 5th International Workshop on Performance, Protection and Strengthening of Structures under Extreme Loading (PROTECT '15), pp: 620-627.

Ţaranu, N., C. Ciprian-ille and R. Oltean, 2011. Experimental study of reinforced concrete column confined with composite membrane. Buletinul Institutului Politehnic din lasi. Sectia Constructii, Arhitectura, 57: 33-45.

Toutanji, H., M. Han, J. Gilbert and S. Matthys, 2010. Behavior of large-scale rectangular columns confined with FRP composites. J. Compos. Constr., 14: $62-71$. 